\title{
Reduced QT Variability and Increased QT/RR Slope in ECG Signals of Depressed Patients with Suicidal Ideation
}

\author{
AH Khandoker ${ }^{1,2}$, V Luthra ${ }^{3}$, Y Abouallaban ${ }^{3}$, MA Hasan ${ }^{4}$, N Chowdhury ${ }^{1}$, HF Jelinek ${ }^{5,6}$ \\ ${ }^{1}$ Khalifa University, Abu Dhabi, UAE \\ ${ }^{2}$ The University of Melbourne, Parkville, Australia \\ ${ }^{3}$ American Center for Psychiatry and Neurology, Abu Dhabi, UAE \\ ${ }^{4}$ Ryerson University, Toronto, Canada \\ ${ }^{5}$ Charles Sturt University, Albury, New South Wales, Australia \\ ${ }^{6}$ Macquarie University, Sydney, New South Wales, Australia
}

\begin{abstract}
Major depressive disorder (MDD) is associated with a number of comorbidities including cardiovascular disease (CVD), with an increased risk of death after myocardial. The aim of this study was to investigate if parameters for ventricular repolarization variability and dynamics in ECG signals are different in MDD patients with/without suicidal ideation and healthy volunteers. Sixty-one ECG recordings (10 minutes) were acquired and analysed from control subjects (44 CONT), $20 \mathrm{MDD}$ subjects with $(M D D S I+)$ and 21 without suicidal ideation [SI] (MDDSI-) for a case-control analysis at a psychiatric clinic in the UAE. The Mini-International Neuropsychiatric Interview (MINI) made diagnoses of $M D D$ and the subscale for was used to evaluate the patients' suicidal intensions [0 to 38]. The subscale for SI consists of 19 items, which was used to evaluate the patients' suicidal intensions [0 to 38]. Then heart ratecorrected $Q T$ interval (QTc), QT/RR slope, $Q T$ variability (QTV), Median T-wave amplitudes and T-wave variability were estimated. MDD patients with suicidal ideation displayed increased QT/RR slope and reduced QTV, which may reflect abnormal ventricular repolarization liability and lead to higher risk of cardiac arrhythmia and future cardiovascular diseases.
\end{abstract}

\section{Introduction}

CVD and depression appear to have bidirectional relationship [1]. Taking into account and controlling for pre-existing cardiovascular risk factors, a recent systematic meta-analysis estimated a combined overall relative risk of 1.54 for the contribution of depression to the onset of CAD [2]. Patients are diagnosed with acute myocardial infarction run an increased mortality risk even when they suffered from low levels of depression, compared to their non-depressed cohorts [3]. Some reports suggest that the cardiac autonomic dysfunction in depressed patients may increase the risk of arrhythmia; which itself is a risk factor for coronary and other cardiovascular disorders [2]. Another study reported a higher prevalence of arrhythmia in depressed patients compared with controls [4]. That people with depression are more vulnerable to arrhythmias, especially supraventricular arrhythmias, such as single atrial premature beats, paired atrial premature beats and single ventricular premature beats [5]. Increased sympathetic nervous system activity in depressed patients might cause the relationship between arrhythmia and emotional turbulence [5, 6].

Fifteen percent of clinically depressed patients die by suicide [7]. Patients with suicidal tendencies exhibited significant and more pronounced cardiac vagal withdrawal compared to healthy counterparts, as well as MDD patients without suicidal ideation [8]. Another study suggested that suicidal ideation is related to altered serotonergic functions [9]. We hypothesize that suicidal ideation in depression may be associated with altered ventricular repolarization heterogeneity as measured by QT interval and T-wave amplitudes variability. Therefore, the aim of this study was to investigate if parameters for ventricular repolarization variability and dynamics in ECG signals are different in MDD patients with/without suicidal ideation and healthy volunteers.

\section{Methods}

\subsection{Data}

Sixty-one ECG recordings (10 minutes) were acquired and analysed from control subjects (44 CONT), 20 MDD subjects with (MDDSI+) and 21 without suicidal ideation [SI] (MDDSI-) for a case-control analysis at a psychiatric 
clinic in the UAE. Participants were recruited from the outpatient clinic at American Center for Psychiatry and Neurology in Abu Dhabi. The study was approved by $\mathrm{Al}$ Ain District Ethics Committee, and all participants provided written informed consent. Diagnoses including history of suicidal ideation were made by a consultant Psychiatrist (Veena Luthra) using the Mini-International Neuropsychiatric Interview (MINI) [9]) and the severity of clinical depression was assessed using the structured interview guide for the Hamilton Depression Rating Scale (HAM-D) [10]. The scale of suicidal ideation consists of 19 items which was used to evaluate a patient's suicidal intention [11] . The minimum score was zero and maximum score was 38. Higher scores indicate greater suicidal ideation. All participants completed the Depression Anxiety and Stress Scales (GAD 7 and PHQ 9), a reliable and valid self-report measure of depression, anxiety, and stress severity (Table 1).

Table 1: Patients' demographics and psychiatric scores

\begin{tabular}{|c|c|c|c|c|c|c|c|c|}
\hline Variable & \multirow{2}{*}{\multicolumn{3}{|c|}{$\begin{array}{c}\text { MDDSI+ } \\
20\end{array}$}} & \multirow{2}{*}{\multicolumn{3}{|c|}{$\begin{array}{c}\text { MDDSI- } \\
21 \\
\end{array}$}} & CONT & \multirow{2}{*}{ p-value } \\
\hline $\mathrm{N}$ & & & & & & & 44 & \\
\hline $\begin{array}{l}\text { Gender } \\
\text { male,\% }\end{array}$ & \multicolumn{3}{|c|}{$5(25 \%)$} & \multicolumn{3}{|c|}{$5(23.81 \%)$} & $20(45.45 \%)$ & \\
\hline Age (yrs) & 33.05 & \pm & 9.60 & 36.00 & \pm & 8.7 & $31.39 \pm 9.85$ & 0.07 \\
\hline WC (cm) & 87.68 & \pm & 15.84 & 88.42 & \pm & 16.96 & $77.5 \pm 9.72$ & 0.00 \\
\hline Height $(\mathrm{cm})$ & 162.70 & \pm & 8.69 & 163.85 & \pm & 8.78 & $162.23 \pm 9.67$ & 0.52 \\
\hline BMI & 26.76 & \pm & 5.84 & 31.68 & \pm & 22.68 & $24.23 \pm 3.48$ & 0.03 \\
\hline SBP & 111.0 & \pm & 13.73 & 113.50 & \pm & 13.48 & $112.21 \pm 10.25$ & 0.67 \\
\hline DBP & 70.50 & \pm & 7.60 & 73.00 & \pm & 7.32 & $72.39 \pm 7.74$ & 0.76 \\
\hline BDI & 36.50 & \pm & 11.57 & 31.38 & \pm & 11.20 & & 0.16 \\
\hline GAD7 & 17.95 & \pm & 9.55 & 14.52 & \pm & 4.50 & & 0.15 \\
\hline PHQ9 & 21.9 & \pm & 10.97 & 17.33 & \pm & 4.97 & & 0.09 \\
\hline $\begin{array}{c}\text { Suicidal } \\
\text { Score }\end{array}$ & 16.95 & \pm & 7.58 & 0.52 & \pm & 1.12 & & 0.00 \\
\hline
\end{tabular}

Abbreviations: $\mathrm{WC}=$ waist circumference; $\mathrm{BMI}=$ body mass index; $\mathrm{SBP}=$ systolic blood pressure; $\mathrm{DBP}=$ diastolic blood pressure; $\mathrm{BDI}=$ beck depression inventory; $\mathrm{GAD7}=$ general anxiety disorder; $\mathrm{PHQ}=$ patients health questionnaire

All patients underwent a supine resting recording of ECG, respiration (Powerlab ADInstruments) and arterial pulse blood pressure by Finometer MIDI (Finapres, Amsterdam). Physiological signals were recorded over 10 minutes using a lead II configuration (Powerlab ADInstruments, Australia) and captured on Labchart 7.1 with a sampling rate set at $1000 \mathrm{~Hz}$ and a notch filter at $50 \mathrm{~Hz}$. Table 1 summarizes the clinical variables of the patient group.

\subsection{Feature extraction from ECG signals}

A typical example of ECG signals with different features that can be extracted from the signal is shown in Figure 1.

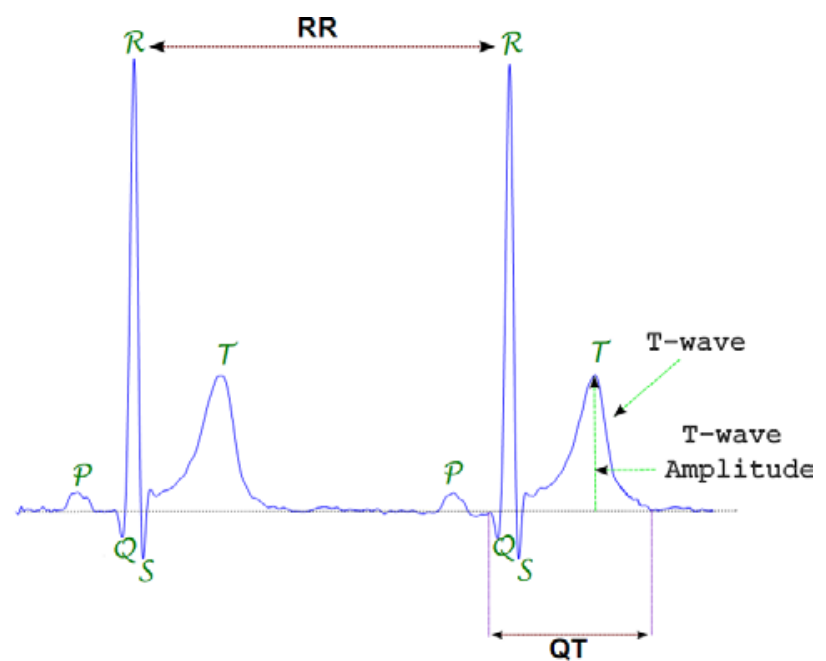

Fig. 1: ECG and arterial pulse signals

In this study, we used template-matching algorithm, which was introduced by Berger and his co-workers [12]. Here, the operator defines a template of the QT interval by selecting the starting point of Q-wave and ending point of T-wave for one beat of ECG [12]. Then the algorithm finds the QT interval of all other beats by determining how much each $\mathrm{T}$-wave must be stretched or compressed in time to best match with the template [12]. We have also calculated the rate-corrected QT interval (QTc) by following the Bazett's formula [13]. The QT/RR relation was analyzed using a linear regression line for each subject $([\mathrm{QT}]=\alpha[\mathrm{RR}]+\beta$; where $\alpha$ is the slope and $\beta$ is the y-intercept). To determine the QTV, we computed the standard deviation of QT intervals. In addition, the QT variability index, QTVI was computed according to the equation given by (Berger et al 1997, [1])

$$
\left.Q T V I=\log _{10}\left[Q T_{v} / Q T_{m}^{2}\right) /\left(R R_{v} / R R_{m}^{2}\right)\right]
$$

where the numerator contains the variance of all QT intervals (QTv) divided by the square of the mean QT interval (QTm), The denominator contains the variance of all RR intervals (RRv) divided by the square of the mean RR interval (RRm).

Moreover, we have also measured the amplitude of the $\mathrm{T}$-waves for each beat by following the same procedure that has been described earlier articles $[14,15]$. Here, the T-wave for each beat was obtained by considering the peak of the voltage deflection within the ST segment of ECG signal. The median of absolute values of the T-wave amplitudes was obtained and used in the subsequent analysis. Finally, the standard deviation of T-wave amplitude was calculated for computing the TWV [16]. 


\subsection{Statistics}

In this study the nonparametric Kruskall-Wallis Tukey-Kramer post hoc examination were carried out to determine differences of ventricular repolarization dynamical features among three groups (MDDSI+, MDDSI- and CONT). $\mathrm{p}<0.05$ was set for significance.

\section{Results}

Table 1: Mean \pm SD values of parameters of Ventricular repolarization variability and dynamics in ECG signals of MDD patients with/without Suicidal Ideation and Control groups. * means significant $(\mathrm{p}<0.05)$ difference between CONT and MDDSI- and $\S$ means significant $(\mathrm{p}<0.05)$ between CONT and MDDSI+.

\begin{tabular}{|c|c|c|c|c|}
\hline & $\begin{array}{l}\text { MDDSI } \\
+ \\
(n=20)\end{array}$ & $\begin{array}{l}\text { MDDSI- } \\
(n=21)\end{array}$ & $\begin{array}{l}\text { CONT } \\
(n=44)\end{array}$ & $\begin{array}{c}p- \\
\text { value }\end{array}$ \\
\hline QT(sec) & $\begin{array}{ll}0.43 & \pm \\
0.03 & \end{array}$ & $\begin{array}{ll}0.43 & \pm \\
0.03 & \end{array}$ & $\begin{array}{ll}0.42 & \pm \\
0.04 & \end{array}$ & 0.246 \\
\hline $\mathrm{QT}_{\mathrm{C}}$ (sec) & $\begin{array}{ll}0.48 & \pm \\
0.02 & \end{array}$ & $\begin{array}{l}0.48 \pm 0.0 \\
3(*)\end{array}$ & $\begin{array}{ll}0.46 & \pm \\
0.03 & \end{array}$ & 0.035 \\
\hline QTVI & $\begin{array}{ll}-1.56 \quad \pm \\
0.52\end{array}$ & $\begin{array}{ll}-1.33 \quad \pm \\
0.53\end{array}$ & $\begin{array}{l}-1.18 \pm \\
0.70\end{array}$ & 0.080 \\
\hline QTV (ms) & $\begin{array}{l}4.65 \pm \\
2.51(\S)\end{array}$ & $\begin{array}{l}4.60 \pm 2.0 \\
8(*)\end{array}$ & $\begin{array}{ll}7.08 & \pm \\
3.30 & \end{array}$ & 0.001 \\
\hline $\begin{array}{l}\text { T-wave } \\
\text { amp (mV) }\end{array}$ & $\begin{array}{ll}0.02 & \pm \\
0.02 & \end{array}$ & $\begin{array}{ll}0.02 & \pm \\
0.02 & \\
\end{array}$ & $\begin{array}{ll}0.03 & \pm \\
0.03 & \end{array}$ & 0.060 \\
\hline $\begin{array}{l}\text { TWV } \\
(\mathrm{mV})\end{array}$ & $\begin{array}{ll}0.04 & \pm \\
0.03 & \\
\end{array}$ & $\begin{array}{l}0.02 \pm 0.0 \\
2(*)\end{array}$ & $\begin{array}{ll}0.05 & \pm \\
0.04 & \\
\end{array}$ & 0.014 \\
\hline $\begin{array}{l}\text { QT_RR_ } \\
\text { slope }\end{array}$ & $\begin{array}{l}0.06 \pm \\
0.03(\S)\end{array}$ & $\begin{array}{ll}0.05 & \pm \\
0.02 & \end{array}$ & $\begin{array}{ll}0.03 & \pm \\
0.04 & \end{array}$ & 0.045 \\
\hline $\begin{array}{l}\mathbf{R R}_{\text {mean }} \\
\text { (sec) }\end{array}$ & $\begin{array}{l}0.83 \pm \\
0.11\end{array}$ & $\begin{array}{l}0.82 \\
0.12\end{array}$ & $\begin{array}{ll}0.83 & \pm \\
0.12 & \end{array}$ & 0.868 \\
\hline $\begin{array}{l}\text { SDNN } \\
(\mathrm{ms})\end{array}$ & $\begin{array}{r}61.96 \\
\pm 33.38\end{array}$ & $\begin{array}{l}50.55 \pm \\
30.35(*)\end{array}$ & $\begin{array}{l}84.03 \\
\pm 43.76\end{array}$ & 0.004 \\
\hline $\begin{array}{l}\text { RMSSD } \\
\text { (ms) }\end{array}$ & $\begin{array}{r}55.82 \\
\pm 43.63\end{array}$ & $\begin{array}{l}43.83 \pm \\
34.85(*)\end{array}$ & $\begin{array}{c}84.07 \\
\pm 51.06\end{array}$ & 0.003 \\
\hline
\end{tabular}

QTc values are prolonged and QTV values are reduced in both MDDSI+ and MDDSI- groups as compared to CONT group. On the other hand, QT-RR Slope of MDDSI+ was found to be higher than that of CONT group. Interestingly, mean RR intervals were not found to be significantly different among three groups. SDNN and RMSSD of HRV of MDDSI- group were significantly reduced as compared to CONT group. However, none of HRV features of MDDSI+ group were significantly different from MDDSI- and CONT groups.

\section{Discussion}

Reduced QTV and elevated QT-RR slope were found in MDDSI+ group. Increased QT/RR slopes were observed in patients at risk of cardiac death including postinfarction patients, long-QT syndrome patients, patients with dilated cardiomyopathy and/or heart failure [23]. QT/RR slopes quantify the links between ventricular repolarization and autonomic nervous system, and, thus, increased QT/RR may reflect increased vulnerability of myocardium to its modulation by autonomic nervous system in MDDSI+ patients group. Previous research showed an association between carriage of the s allele of the serotonin transporter polymorphism (5-HTTLPR) and elevated urinary norepinephrine levels which is related to sympathetic nervous activation [17]. Sympathetic activation to the heart occurs in patients unexpectedly developing ventricular tachycardia and ventricular fibrillation [18]. Another study reported the follow up of selective serotonin reuptake inhibitor therapy that sympathetic nervous activity was significantly reduced only in those patients with excessively elevated sympathetic tone [19].

Since the QTV is elevated in CHF [12](2), and sympathetic tone is also elevated in heart failure [20], it was postulated that QT variability is a measure of cardiac sympathetic tone. However, our study showed that QTV are reduced in MDD groups. Baumert et al. [21] recently found that QT variability measures did not correlate with norepinephrine levels in blood sampled from the coronary sinus in 17 subjects with depression and panic disorder, challenging the notion that beat-to-beat QT variability measurement provides an assessment of cardiac autonomic activity [22]. Features used in our study did not find any significant difference between MDDSI+ and MDDSI- groups, however, it could provide the usefulness of QT/RR slope and QTV to identify MDD patients who are at risk of ventricular arrhythmia.

\section{Acknowledgements}

This study was supported by a Khalifa University Internal Fund (KUIRFL1) and partially by American Center for Psychiatry and Neurology, Abu Dhabi, UAE.

\section{References}

[1] Nemeroff CB, Goldschmidt-Clermont PJ. Heartache and heartbreak-the link between depression and cardiovascular disease. Nature Reviews Cardiology. 2012;9:526-39.

[2] Wulsin LR, Singal BM. Do depressive symptoms increase the risk for the onset of coronary disease? A systematic quantitative review. Psychosomatic medicine. 
2003;65:201-10.

[3] Bush DE, Ziegelstein RC, Tayback M, Richter D, Stevens $\mathrm{S}$, Zahalsky $\mathrm{H}$, et al. Even minimal symptoms of depression increase mortality risk after acute myocardial infarction. The American Journal of Cardiology. 2001;88:337-41.

[4] Wang Y, Zhao X, O'Neil A, Turner A, Liu X, Berk M. Altered cardiac autonomic nervous function in depression. BMC psychiatry. 2013;13:187.

[5] Zhou J, Li X, Zhao S. The clinical analysis of anxiety depression in cardiovascular patients. The Journal of Medical Theory and Practice. 2004;1:011.

[6] Rozanski A, Blumenthal JA, Kaplan J. Impact of psychological factors on the pathogenesis of cardiovascular disease and implications for therapy. Circulation. 1999;99:2192-217.

[7] Chang HA, Chang CC, Chen CL, Kuo TB, Lu RB, Huang SY. Major depression is associated with cardiac autonomic dysregulation. Acta Neuropsychiatrica. 2012;24:318-27.

[8] Wells CL. A Comparison of Suicidal Ideation Between Active Duty Military and Military Dependents Outpatients: A Retrospective Study Identifying Treatment Outcome Using the Outcome Questionnaire-45.2: ProQuest; 2008.

[9] Sheehan DV, Lecrubier Y, Sheehan KH, Amorim P, Janavs J, Weiller E, et al. The Mini-International Neuropsychiatric Interview (MINI): the development and validation of a structured diagnostic psychiatric interview for DSM-IV and ICD-10. Journal of Clinical Psychiatry. 1998.

[10] Williams JB. A structured interview guide for the Hamilton Depression Rating Scale. Archives of General Psychiatry. 1988;45:742-7.

[11] Beck AT, Steer RA, Ranieri WF. Scale for suicide ideation: Psychometric properties of a self-report version. Journal of Clinical Psychology. 1988;44:499-505.

[12] Berger RD, Kasper EK, Baughman KL, Marban E, Calkins H, Tomaselli GF. Beat-to-beat QT interval variability novel evidence for repolarization lability in ischemic and nonischemic dilated cardiomyopathy. Circulation. 1997;96:1557-65.

[13] Bazett HC. An analysis of the time-relations of electrocardiograms. Heart. 1920;7:353-70.

[14] Hasan MA, Abbott D, Baumert M. Relation between beatto-beat QT interval variability and T-wave amplitude in healthy subjects. Annals of Noninvasive Electrocardiology. 2012;17:195-203.

[15] Hasan M, Abbott D, Baumert M. Beat-to-beat QT interval variability and T-wave amplitude in patients with myocardial infarction. Physiological Measurement. 2013;34:1075.

[16] Hasan MA, Abbott D, Baumert M, Krishnan S. Increased beat-to-beat T-wave variability in myocardial infarction patients. Biomedical Engineering/Biomedizinische Technik 2016;(under revision).

[17] Otte C, McCaffery J, Ali S, Whooley MA. Association of a serotonin transporter polymorphism (5-HTTLPR) with depression, perceived stress, and norepinephrine in patients with coronary disease: the Heart and Soul Study. American Journal of Psychiatry. 2007.

[18] Meredith IT, Broughton A, Jennings GL, Esler MD. Evidence of a selective increase in cardiac sympathetic activity in patients with sustained ventricular arrhythmias. New England Journal of Medicine. 1991;325:618-24.

[19] Barton DA, Dawood T, Lambert EA, Esler MD, Haikerwal D, Brenchley C, et al. Sympathetic activity in major depressive disorder: identifying those at increased cardiac risk? Journal of Hypertension. 2007;25:2117-24.

[20] Kaye DM, Lefkovits J, Jennings GL, Bergin P, Broughton A, Esler MD. Adverse consequences of high sympathetic nervous activity in the failing human heart. Journal of the American College of Cardiology. 1995;26:1257-63.

[21] Baumert M, Lambert GW, Dawood T, Lambert EA, Esler MD, McGrane M, et al. QT interval variability and cardiac norepinephrine spillover in patients with depression and panic disorder. Am J Physiol Heart Circ Physiol. 2008;295:H962-H8.

[22] Malik M. Beat-to-beat QT variability and cardiac autonomic regulation. American Journal of PhysiologyHeart and Circulatory Physiology. 2008;295:H923-H5.

[23] Cygankiewicz I1, Zareba W, Vazquez R, Almendral J, Bayes-Genis A, Fiol M, Valdes M, Macaya C, GonzalezJuanatey JR, Cinca J, Bayes de Luna A; MUSIC Investigators. Prognostic value of QT/RR slope in predicting mortality in patients with congestive heart failure. J Cardiovasc Electrophysiol. 2008 Oct;19(10):1066-72.

Address for correspondence.

Name. Dr Ahsan Khandoker

Full postal address. Department of Biomedical Engineering, Khalifa University, Abu Dhabi, PO Box 127788, UAE.

E-mail address (optional). ahsan.khandoker@kustar.ac.ae 